\title{
Plotino y el problema del yo: una aproximación a su antropología filosófica a través del estudio del mal
}

Massiel Román Molero

Pontificia Universidad Católica del Perú

Resumen: El propósito del presente trabajo es realizar una aproximación a la antropología de Plotino al abordar los niveles (o layers) del yo (self) a partir de una problematización de la concepción del mal -metafísica y ética- expresada principalmente en Enéadas V 1, 1, 1-15 y I 8, 3, 35-40. Para ello, en la primera sección se revisará escuetamente el papel de la materia en la procesión. En la segunda sección, se estudiará la problemática entre la concepción metafísica y ética del mal, y su relación con los niveles del yo. En la última sección se aborda la pregunta por algún valor de índole epistémica de la existencia del mal para el filósofo en la distinción dialéctica del verdadero yo del hombre.

Palabras clave: Plotino, yo, mal, materia, alma superior

Abstract: The purpose of this paper is to present an approach to Plotinus' anthropology by addressing the levels (or layers) of the self from a problematization of the conception of evil -metaphysical and ethical-expressed mainly in the Enneads $\mathrm{V} 1$, 1, 1-15 and I 8, 3, 35-40. For this, in the first section the role of matter in the procession will be briefly reviewed. In the second section, I will focus on the study of the problem between the metaphysical and ethical conceptions of evil, and its relation to the levels of the self. In the last section, I will address the question regarding the epistemic value of the existence of evil for the philosopher in the dialectical distinction of the true self of the human being.

Keywords: Plotinus, self, evil, matter, superior soul 


\section{§1. Introducción}

Aunque Plotino (203-270 d.C.) ${ }^{1}$ se refiera a sí mismo como un exégeta de su maestro Platón, su filosofía transforma y trasciende, con una lectura bastante peculiar y propia, a Aristóteles y Platón. Entre los problemas que Plotino abordó, el de la interioridad y el ser-humano emerge como uno de los más acuciantes e importantes en las Enéadas. En un complejo sistema que da cuenta de la arquitectura de la realidad, Plotino trazó una línea muy estrecha entre antropología, ética y metafísica. De ahí que no sorprenda que el conocimiento de sí mismo sea un instrumento fundamental para la conversión y ascenso del alma hasta su unión con lo Uno (VI 7, 41, 1525). Pero, ¿qué -o quién- es este hombre del cual Plotino habla?, ¿qué lo conforma?

Visto de manera muy general, para él este "yo" del hombre puede entenderse en diversos niveles. Plotino dice que, para entender quién es él, uno debe diferenciar entre el revestimiento de hombre y el hombre verdadero (I 1). Por un lado, está el animal total, al yo "dianoético" y físico, al sujeto de los placeres, penas, temores y apetitos. Por otro lado, está el hombre verdadero en tanto yo "noético", sujeto de la intelección y contemplación del principio divino de la realidad, quien permanece"(...) puro de las afecciones, poseyendo las virtudes intelectivas (...)" (I 1, 10, 5-10). Mas, ¿cómo se relaciona este hombre con su mundo?, ¿cómo da cuenta de su actitud ante un mundo que "consta de contrarios"? En una realidad en la que "(...) no pueden desaparecer los males (...)" (III 2, 5, 30) -esto es, están por necesidad $(\mathbf{8}, 7)$ - y cuya presencia en la vida moral es ineludible, ¿cómo se ve la antropología influida o afectada por su existencia?

Dado que las dimensiones del problema del "sí mismo" humano son tanto metafísicas como éticas, en el presente trabajo realizaré una primera aproximación a la antropología de Plotino a partir del estudio de algunos aspectos del mal. Para ello, en la primera sección haré una revisión escueta al papel de la materia en la procesión. En la segunda sección, con énfasis en

1 Igal plantea que es probable que, si Plotino murió a mediados del 270, nació en la segunda mitad del año 203 o en la primera mitad del 204 (1985, 7-8). 
algunos pasajes de I 1, I 8 y || 4, estudiaré la problemática entre la concepción metafísica y ética del mal, y su relación con los niveles del yo. Finalizaré con una pregunta acerca de si la existencia del mal tiene algún valor de índole epistémica para el filósofo en la distinción, mediante la dialéctica, del verdadero yo del hombre.

\section{§2. La estructura de la realidad}

La realidad está constituida por una escala ascendente de grados de contemplación. Es intelección y contemplación y, por lo mismo, es vida. O, visto de otra forma, "(...) toda vida es una determinada intelección, solo que una es más borrosa que otra, como lo es también la vida" (III 8, 8, 10-15). En ese sentido, es natural que todos los seres aspiren a contemplar y que este deseo vaya desde la Naturaleza (Phýsis) hasta la Inteligencia (Noûs). La forma en que la realidad se despliega y constituye se conoce como procesión. Según Bréhier, esta enfatiza y refiere la concatenación, dependencia y jerarquía entre los distintos "niveles" de la realidad (1958, 61-62).

En la progresiva unificación de la realidad es posible encontrar la fuente de su dinamismo y belleza, el Uno. En efecto, en palabras de Plotino: "Por eso el término de reducción en todos los casos es un uno. Es decir, en cada caso, el término de reducibilidad es un uno particular, y este universo es reductible al uno anterior a él, no al Uno sin más, y así hasta llegar al Uno sin más; este, en cambio, ya no es reductible a otro" (III 8, 10, 20-25). La unidad es fuente de vida porque es anterior a toda multiplicidad. El Uno es "(...) la nada en el sentido de ninguna de las cosas de las que es principio [negātiōnis], pero es tal que, no pudiendo predicarse nada de él, no el ser, no la esencia, no la vida, es lo que sobrepasa todas las cosas [ēminentiae]" (III 8, 10, 30-35) y, de cierta manera, es todas las cosas [analogiae]. $Y$ esto es posible porque

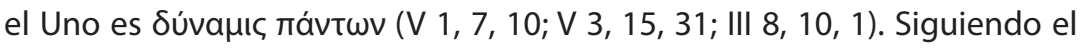
principio de procreación por el estado de perfección, resulta natural que del Uno provenga lo más perfecto, esto es, la Inteligencia ${ }^{2}$ (V $\left.16,40-42\right)$.

2 La complejidad de esta hipóstasis rebasa con mucho el contenido de este trabajo. No voy a detenerme en su tratamiento. 
Como hipóstasis autoconstituyente, la Inteligencia interviene en su propio perfeccionamiento. Esbozaré rápidamente la teoría de su génesis en dos momentos. En una primera fase, la Inteligencia es capacidad intuitiva, vista en potencia, vacía de contenido (V 3, 11,5). La Inteligencia necesita de la alteridad para ser, sin ella se haría una sola cosa y se callaría (V 1, 4, 35-40). En su segunda fase, la Inteligencia necesita detenerse para darse "vuelta" hacia el Uno y ver. La Inteligencia actúa como sujeto y el Uno como objeto de deseo.

En este punto y, desde luego, en función al propósito de este trabajo, parece preciso revisar la "materia inteligible" de la que habla Plotino especialmente en II 4, 5, 25-40. La materia inteligible, en contraste con la materia ${ }^{3}$, no es solamente indeterminación; es un valor positivo porque es potencialidad (capacidad intuitiva, en el caso de la Inteligencia). En II 4, 5, 35, Plotino dice que "(...) tanto el movimiento como la alteridad proveniente del Primero son algo indefinido y necesitan de aquel para definirse; pero se definen una vez vueltos a él; antes, en cambio, tanto la materia como la alteridad son algo indefinido y no bueno todavía". La indefinición de esta materia no debe ser menospreciada porque sí cumple la condición de estar en la disposición de ofrecerse a los seres que le preceden 4 . Al recibir aquello que la define, la materia divina posee una vida definida e intelectiva (II 4, 5, 15 20) y su conformación es real.

Así pues, "la materia inteligible es, por un lado, el sujeto indefinido que procede del Uno y, por otro, la potencialidad del sustrato cumplido por su forma, pero generado por el poder sustancial que lo acompaña y lo hace aquello que es" (Corrigan 1998, 290; la traducción es mía). Pero, ¿a qué realidad se refiere Plotino con este tipo de materia? En el caso de la Inteligencia, esta sería la primera fase de su actividad 5 . En ese tránsito, la Inteligencia,

3 También llamada "materia inferior".

4 "Ahora bien, si aquella realidad, aun siendo múltiple, es indivisa, es que las muchas Formas, estando en una sola cosa, están en la materia, que es esa sola cosa, mientras que ellas son conformaciones de la misma. En efecto, esa sola cosa concíbela como varia y multiforme. Por lo tanto, ella misma es informe antes de ser varia". Para Igal, aquí existe una clara alusión a la génesis bifásica de la Inteligencia $(1985,417)$.

5 Siguiendo el tratado III 9, 5, también podría incluirse al alma, en tanto sirve como materia a la Inteligencia, porque es esta hipóstasis la que la perfecciona a través de sus lógoi y, en 
por ser actividad noética pura, separa y divide lo que como Uno era sin límite, sin forma alguna. En su intento de captar su simpleza, lo pluraliza y genera las Ideas. La Inteligencia está procediendo, convirtiéndose, contemplando y pluralizando al Uno eternamente. La Inteligencia intelige las Ideas simultáneamente, todas a la vez, pero ello no implica que sean cosas completamente distintas, por el contrario: “(...) ella misma es su actividad: Inteligencia e intelección son una sola cosa” (Igal 1992, 47).

Si la Inteligencia es imagen del Uno, el Alma lo es de la Inteligencia ${ }^{6}$. En palabras de Plotino, es por el mismo mecanismo de la procesión que el Alma se genera y, además, como hipóstasis autoconstitutiva, su manera de perfeccionarse es análoga a la de la Inteligencia: "La inteligencia del Alma se ocupa de los raciocinios y su perfeccionamiento le viene, de nuevo, de la Inteligencia cual de un padre que crió al hijo al que había engendrado imperfecto comparado consigo. Al Alma le viene, pues, su entidad de la Inteligencia y su razón en acto de su visión de la Inteligencia. Porque cuando el Alma pone su mirada en la Inteligencia, recibe de dentro y como propio lo que piensa y actualiza" (V $13,15-20)$. Hasta aquí, el esquema es el mismo. Sin embargo, dentro del alma también se realiza otra "procesión".

El Alma tiene dos "partes": el Alma superior y el Alma inferior (o también llamada Phýsis). Plotino expresa en III 9, 3, 10 que el alma”, al “(...) querer volverse hacia sí misma, crea lo posterior a ella como imagen de sí misma, cual adentrándose en la oquedad del no-ser y haciéndose más indeterminada", lo cual se puede entender como esta "alma inferior". Aquí la actividad contemplativa se da en ambos niveles, pero no de la misma manera. Mientras que la actividad contemplativa del alma superior es perfecta, para la Naturaleza o Phýsis, su actividad está ya desgastada, desvaída, y termina debilitándose hasta ser acción. Todos los contornos de los cuerpos se "desprenden" por sí solos sin que esta haga nada más que contemplarse a sí misma (III 8 4, 5-10).

última instancia, de la vuelta del alma a ella.

6 No entraré tampoco en los pormenores de la constitución de la hipóstasis Alma, solo revisaré su estructura en función del origen de la materia.

7 En seguida trataré el problema de si se trata del alma particular o el alma universal en este tratado. 
Siguiendo la lectura de III 9 3, 10, Plotino también dice que “(...) la imagen totalmente indeterminada de esa imagen es oscura porque está totalmente desprovista de razón y de inteligibilidad y muy alejada del ser". ¿Qué podría ser esta imagen de imagen? Si según esta interpretación la primera imagen corresponde al alma inferior, la segunda imagen tendría que ser la materia. Ahora bien, el origen de la materia no es exactamente uno de los temas más cristalinos en Plotino ${ }^{8}$. Para empezar, este dice sobre la Vegetatividad ${ }^{9}$ que "[e]ngendra algo completamente distinto de ella, porque después de ella ya no hay vida, sino que lo engendrado por ella carece de vida". Y agrega:"(...) así también aquí lo engendrado debe ser no ya una especie de alma -pues no vive ya-, sino indeterminación absoluta" (III 4, 1, 1-15). Había indeterminación también antes, pero era indefinición "en una forma", relativa a su propio perfeccionamiento. Sin embargo, en III 9, se especifica que es el alma particular la que genera la materia por volverse hacia sí misma. Sumado a esto, en I 8, uno de los últimos tratados de Plotino, se dice que el alma engendró a la materia como resultado de "alguna pasión" $(14,50)$. ¿Cómo conciliar estas afirmaciones?

Opto por adoptar la posición de Corrigan (1998) frente a O'Brien (1971): el alma particular es sustancia, no por ser el alma de una parte, sino en virtud de ser toda el alma $(1998,162)$. Antes de entrar en cierto detalle, me parece que el concepto de sympátheia podría ser de utilidad para este pasaje. Aquí sigo a Gurtler (1988) en Hutchinson (2018), quien centra su discusión en la aplicación de este concepto para la relación de unidad entre el alma del mundo y la unificación del cosmos. Además, para Hutchinson, este concepto, en tanto característica objetiva de un ser viviente, es responsable de constituirlo como un todo ordenado y coherente ${ }^{10}(2018,89)$. En virtud de esta sympátheia, pues, y, sobre todo, de esta característica del alma particular señalada al inicio, me parece pertinente optar por concebir a la materia como originada por el alma, la cual es una sustancia y realidad

8 Este debate ha sido ampliamente abordado por diversos académicos. Por cuestión de extensión y tiempo, la consulta al respecto ha sido bastante limitada. He consultado textos de O’Brien (1971, 1996), Rist (1974), Igal (1992) y Corrigan (1998).

9 Esto es, según Igal (1992), el Alma Vegetativa, aunque Plotino también la llama Alma Universal.

10 Sobre la importancia de este concepto en la conciencia volveré en la segunda sección de este trabajo. 
integral en la que se incluyen, desde luego, tanto el alma universal como el alma particular. Esto haría que no hubiese una contradicción y, para este trabajo, aunque no solucione el problema, es suficiente.

Sobre la base de lo expresado por Platón en el Sofista sobre el no-ser como alteridad, Plotino concibe en I 8 y II 4 a la materia como diferente al ser y, en ese sentido, un no-ser ${ }^{11}$. La indeterminación e indefinición de la materia le permiten ser sustrato de "todas las cosas" $y$, con ello, receptora de contrarios. Es ilimitada, carece de cualidades y, por lo tanto, es privación total. Es lo contrario a la sustancia; es una apariencia de ella ${ }^{12}$. Es forzosamente mala porque está falta de bien; está en penuria absoluta (II 4, 16, 20; I 8, 3, 15). Es en este eslabón de la procesión en el que se da un quiebre: todas las anteriores realidades son capaces de volver la vista hacia su principio y unirse con él salvo la materia. La materia, siendo indeterminación absoluta, carece de actividad e iniciativa, es una sombra que aguarda lo que la causa activa quiera causar en ella (Igal 1992, 72). Así pues, es el alma inferior la que, a nueva cuenta, se voltea a ver a la materia para estructurarla y proyectar sus lógoi, de manera tal que es así como se genera el mundo sensible.

Ahora bien, esto es una aproximación a cómo se generó la materia, pero no responde por qué. ¿Cómo es posible, pues, que la materia sea generada por una pasión (páthos) del alma? En última instancia, ¿cómo puede del alma surgir la materia, que es mala? En este punto sigo la interpretación de Rist: en el alma hay potencialmente dos tipos de "debilidades" de índole "moral" (1974, 502). En I 8, 14, 50, Plotino dice que la materia es causa de la debilidad y del vicio del alma, ante lo cual resulta interesante preguntarse, tal como lo hace O'Brien: ¿cómo es posible que, de ser causa de la debilidad en el alma, su origen sea efecto de una debilidad "anterior" en ella? Para Rist, no hay contradicción si se introduce el rol de la potencialidad: "La materia no tiene existencia por sí misma y, aun así, de alguna manera, está presente en el alma, al menos potencialmente, antes de que aparezca en los objetos

11 Para poder concebir "racionalmente" la materia se necesita separarla mentalmente del alma (IV 3, 9, 18-19).

12 "Matter, Plotinus argues, can be non-substance or anti-substance (he me ousia), not as the negation of individual substance, but rather as the universal negation of all beings, by virtue of its universal opposition to form" (Corrigan 1998, 206). 
materiales como un mal absoluto actual" (1972, 503; la traducción es mía). Esto no implica que las almas particulares sean malas por contener "potencialmente" a la materia en sí; no es posible, las almas son vida y la materia está muerta, pero es uno de sus productos. Las almas contienen en sí la posibilidad de privación de bondad moral y, en ese sentido, en potencia, a la materia.

En lo siguiente, revisaré las dos debilidades del alma. Aunque Rist se refiera a ellas como "debilidades", quizá podría ser más adecuado denominarlas "tendencias" o "propensiones" del alma de acuerdo a su naturaleza. Ambas implican cierto grado de imperfección, pero la debilidad (weakness) es un término que se utiliza ya para hablar de la actualidad de la materia. En el caso de la primera propensión del alma, él la identifica como la debilidad que lleva al alma a la generación de la materia por verse ella a sí misma (self-willing). La segunda sería, pues, la que lleva al alma a ser "seducida" por la materia después que ha sido generada. Me parece que el problema con esta forma de concebir esta tendencia potencial del alma es que, de cierta manera, pareciese descuidar lo expresado por Plotino en IV 8, 6 y I 8, 7.

En un contexto en el que se habla de que las hipóstasis son realizaciones de las posibilidades del Uno, Plotino hace la siguiente acotación sobre la existencia de las realidades a partir del Alma: “(...) del mismo modo, tampoco debían existir solo almas sin que hicieran su aparición los seres originados por ellas, si es verdad que a cada ser le es inherente por naturaleza la capacidad de producir lo siguiente y la de desarrollarse a partir de algún principio indiviso, a modo de semilla, que se encamine hasta lo sensible como final" (IV 8, 6, 1-10). Para la existencia del mundo sensible es necesaria (anánkē) la existencia de la materia y, más aún, para el despliegue de las potencialidades del alma. Más allá de eso, el Alma como hipóstasis es mucho menos perfecta en relación a sus antecesoras. Hecha esta revisión a la estructura de la realidad, en el apartado siguiente me detendré en la relación entre la hipóstasis Alma y la Materia en función al hombre. 


\section{§3. El problema del mal y el sí mismo del hombre}

En la sección anterior no entré en detalle sobre la identificación que establece Plotino entre el mal y la materia sensible: La materia es el mal en sí. La materia es una apariencia de sustancia que subyace a las figuras sensibles; está adornada con aquello que el alma inferior esté dispuesta a darle, pues no puede poseer bien alguno. Comparada con los seres, “(...) es un fantasma (...) que el razonamiento descubre que es el Mal primario y el Mal en sí" (I 8, 3, 35-40). Para Plotino, la materia es contraria al Bien, a pesar de no ser una sustancia real y verdadera, porque en ella se dan las características contrarias a la otra $(18,6,35-40)$. Lo que se vuelve malo por participación o asemejamiento al mal de la materia es un mal secundario; aunque es factible aducir que esto se da en los cuerpos, ello no los hace automáticamente malos. La materia es causa necesaria para el mal, pero no suficiente. El vicio es dado, pues, cuando la facultad discursiva del alma se ve impedida de ver por sus pasiones y por su inclinación a la materia.

En V 1, 1, 1-15, Plotino expresa lo siguiente:" Para las almas el principio de su mal es la osadía y la generación y la alteridad primera y el querer, en fin, ser de sí mismas". A partir de este pasaje, se podría decir simplemente que este mal en los hombres es mal secundario que se da por el vicio. $Y$, sin embargo, uno se enfrenta a la siguiente interrogante: ¿Por qué sería malo para un alma, emparentada (y guardando cierta identidad) con las hipóstasis, querer ser de sí misma?, ¿cómo conciliar estas afirmaciones? Propongo abordar el problema del mal desde una perspectiva distinta a la anterior: ¿qué es este "sí mismo" del hombre?

En el penúltimo tratado que escribió, Plotino se pregunta qué somos no-

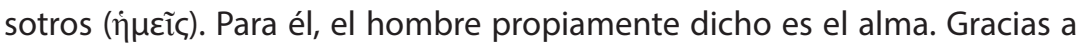
la "procesión" que se despliega en el alma, esta tiene dos "partes", el alma superior e inferior. Asimismo, es una y múltiple; pero en qué sentido lo es se precisará ahora. Para Plotino, el alma superior permanece siendo indivisa, esto es, una, porque no entra en contacto con cuerpo alguno, es inmune a cualquier división espacio-temporal. Sin embargo, el alma inferior es múltiple porque, aun permaneciendo entera por ser una imagen del alma superior, son los cuerpos los que no pueden recibirla y, al encarnarse ella, 
se hace divisible en ellos (I 1, 8, 15-20; IV 2, 1, 75; IV 3, 19, 5-10). El alma superior está junto a los inteligibles; y el alma inferior, aunque en apariencia, mezclada con el cuerpo.

El yo del hombre se puede entender a partir de las consideraciones anteriores. Al respecto, Plotino dice:"Y precisamente de estas formas, de las que el alma recibe ya, ella sola, su señorío sobre el animal, es de donde provienen los razonamientos, las opiniones y las intelecciones. Y aquí es donde prin-

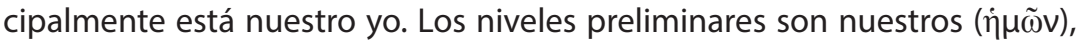
pero 'nosotros' somos lo ulterior y presidimos desde arriba al animal. Pero no habrá dificultad en llamar animal al conjunto, mixto en su parte inferior, mientras que lo de ahí para arriba coincide aproximadamente con el hombre verdadero" (I 1, 7, 15-25).

Quisiera resaltar dos puntos de este pasaje. Por un lado, Plotino, dice que

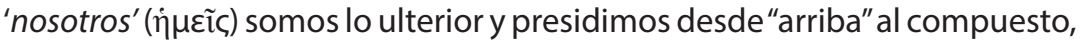
desde aquel "lugar" del que provienen los lógoi que hacen posible que razonemos, opinemos, etc. Por otro lado, los niveles preliminares son nuestros (j $\mu \tilde{\omega} v)$ y pertenecen al animal, al conjunto de alma y cuerpo, al hombre en apariencia. Estando el alma superior siempre vuelta hacia los inteligibles, se podría decir que el alma inferior está meramente vuelta hacia lo sensible, pero este asunto resulta ser más complicado de lo que podría parecer, ya que Plotino habla de niveles ${ }^{13}$ del yo.

Es preciso revisar primero las funciones de los niveles (o "capas") preliminares del yo: el yo físico y el yo dianoético. Empezaré por el yo "físico" o rastro del alma. En II 3, 9, 21-25 y en IV 4 18, 1-9, Plotino menciona la existencia en el compuesto de un rastro (íkhnos), una sombra del alma, imagen del alma Vegetativa o Phýsis proyectada en la materia ${ }^{14}$. Este rastro del alma es necesario para que el organismo del cuerpo tenga vida. A partir de él, los seres humanos tienen capacidades comúnmente asociadas a la vida de las plantas como nutrición, reproducción y crecimiento. ¿De qué manera "la

13 Debido a la extensión del trabajo, no pretendo abordar extensa y hondamente el interesante tema de la conciencia en Plotino.

14 No trataré en detalle el argumento que esgrime Plotino a favor de la existencia de este rastro del alma. Sin embargo, una explicación interesante se puede encontrar en Noble (2013). 
parte pasional del alma" puede considerarse como un "yo"? Hutchinson, al extender la conciencia (awareness) que posee el Universo de sí mismo a cada parte de él, arguye que en cada nivel del self humano existe synaísthēsis ${ }^{15}$ como un tipo de consciencia $(2018,41)$. Junto a sympátheia ${ }^{16}$, su función en este nivel del yo es unificar el cuerpo en un sujeto y hacer que este reconozca qué partes corporales y actividades internas le corresponden. Por estas dos facultades es posible que, en tanto cuerpo, se puedan recibir los estímulos externos y capacidades cognitivas de mayor y menor orden. Ellas proveen una estructura en la que las almas individuales pueden "situarse" (IV 3, 9, 20-25).

El yo dianoético es la parte "intermedia" que el hombre puede orientar hacia "arriba" (hacia la Inteligencia y el Principio) o hacia "abajo" (el mundo sensible y, en última instancia, la materia) (V 1, 11, 5-10). Los poderes en virtud de los cuales el alma inferior cuida el cuerpo sin ser afectada por él son (i) la imaginación y (ii) el razonamiento discursivo. Respecto a (i), ciertamente "nosotros" somos capaces de recibir dos tipos de aportes o entradas (inputs): las del alma superior y las de la potencia sensitivo-perceptiva (V $3,3,35-40)$. En la conciencia del animal, estos dos tipos de entrada son ordenados y regulados por la imaginación. El alma se hace consciente de objetos sensibles e inteligibles y los aprehende mediante imágenes; la imaginación las coordina y conecta en una experiencia unitaria.

(ii) De las dos clases de inteligencia que hay en el alma, a este yo le pertenece la que raciocina ( $V 1,9,15-20)$, la que tiene aquí su asiento (25-30). A través del razonamiento discursivo, el alma procesa, evalúa, juzga las imágenes y las expresa mediante el lenguaje. A diferencia del otro tipo de inteligencia, esta discurre: implica sucesión, memoria, aprendizaje, tiempo y error, pues no está en contacto íntimo ni en identificación total con las Formas. Así pues, al respecto, Bréhier dice: "Las funciones normales del espíritu, razonamiento, memoria, sensibilidad, no son el centro sino derivaciones, limitaciones de la vida espiritual". Y agrega: "Para Plotino, la conciencia, lejos de ser lo esencial, es un accidente, y algo así como un relajamiento" (1958,

15 IV 4, 24, 21-24.

16 Véase especialmente IV 4, 32, 14-19. 
98). Aunque creo que la primera parte de esta cita es bastante acertada porque para ascender en la realidad el hombre necesita desprenderse de aquellas funciones, la segunda afirmación puede matizarse y discutirse un poco.

Plotino señala que:

(...) el pensamiento parece consistir, en general, en la conciencia (synaísthēsis) del todo cuando, siendo varios los componentes de un mismo ser, éste se piensa a sí mismo. En esto precisamente consiste el pensamiento en sentido propio. En cambio, cada componente, por sí solo, es algo y no busca nada. Y si el pensamiento es de algo externo, será deficiente, y no es pensamiento propiamente dicho. Ahora bien, el absolutamente simple y sustantivamente autosuficiente no necesita de nada, mientras que el autosuficiente en sentido secundario pero necesitado de sí mismo, ése sí que necesita pensarse a sí mismo. El deficiente respecto a sí mismo, merced a la totalidad alcanzada cuando consta de todos sus componentes, hace efectiva su autosuficiencia juntándose consigo mismo y volviéndose a sí mismo (V 3, 13, 12-24).

Con esto en cuenta, manifestar que la conciencia, incluida como está en las funciones cotidianas del espíritu, es una limitación o un accidente, podría resultar parcialmente problemático. Primero, no niego que la conciencia humana sea imperfecta: eso es un hecho. Segundo, me parece que englobar las distintas dimensiones de la conciencia humana como una limitación es ciertamente problemático (dentro de poco intentaré mostrar por qué). Tercero, en los hombres -y en ella, por ende- hay una potencial supraconciencia (con relación a las realidades superiores) que podría tomarse como un ahondamiento en la realidad de la conciencia actual. Asimismo, como se vio en la primera parte de este trabajo, los niveles ontológicos y epistemológicos de la realidad son niveles de contemplación. La conciencia permite al ser humano asimilar estos niveles de realidad, pero para llegar a una contemplación divina primero se debe hacer un trabajo dialéctico, el cual es una actividad consciente porque inicialmente es racional. Sobre esto volveré más adelante; por ahora, me parece que los aspectos mencionados podrían implicar que no toda la conciencia es un accidente para Plotino. A propósito de ello, me detendré en la forma como se despliega esto en el yo dianoético. 
Hutchinson plantea que los modos de conciencia que se dan en este yo son antílēpsis, parakoloúthēsis y sýnesis (2018,68-69). A continuación, referiré brevemente qué es cada uno de ellos. Antílēpsis es el tipo de conciencia que mencioné respecto del papel de la imaginación: es indirecta y mediada porque el alma se vuelve consciente de $\mathrm{X}$ cosas a partir de imágenes ${ }^{17}$. $\mathrm{Pa}$ rakoloúthēsis, para este autor, es el único modo de conciencia que Plotino critica $^{18}$. En este tipo de conciencia hay dos actividades: una de primer orden que es pensar, y la segunda que es pensar que se piensa. El problema para el yo dianoético es que en su nivel ambas se dan por separado, no hay una identificación plena entre ellas, y es por eso que la segunda puede interferir en la actividad de la primera $(2018,42)$. Como menciona Hutchinson, “(...) es un tipo de conciencia que pluraliza; separa lo pensado y el pensante en objeto y sujeto" (2018, 42; la traducción es mía).

Finalmente, sýnesis es un tipo de conciencia mediante la cual el hombre reconoce algo similar a su naturaleza superior, esto es, lo inteligible presente en lo sensible. Un ejemplo de esto puede verse en el siguiente pasaje: "De nuevo, pues, reanudando el tema, digamos lo primero en qué consiste por cierto la belleza que hay en los cuerpos. Efectivamente, es algo que se hace perceptible ${ }^{19}$ (sýneîsa) aun a la primera ojeada, y el alma se pronuncia como quien comprende y, reconociéndolo, lo acoge y como que sea ajusta con ello" $(I 6,2)$. Lo interesante -y que, en cierto modo, explicaría por qué este tipo de conciencia es "especial"- de la "percepción" de la belleza para el alma es que la belleza lleva en sí la gracia (kháris) del Bien que no solo

17 Kalligas resalta también el uso de este tipo de conciencia en Plotino: "Interestingly, what P. calls antilēpsis ("apprehension") corresponds to what Alexander terms noēsis ("thought" or "intellection"), given that the latter does not believe in the existence of separate Forms (see De an. 88.13-17, and De an. mant. 110.17-20). The term antilēpsis itself, signifying a process by which representations deriving from both sensation and intellection are jointly apprehended" $(2014,120)$.

18 El pasaje en el que se puede ver este uso de conciencia es el siguiente:"cuando pensamos y cuando obramos, no comportan el que seamos conscientes (tò parakoloutheîn) de ellos: el que está leyendo no es necesariamente consciente (parakoloutheîn hōti) de que está leyendo, sobre todo cuando lee con intensidad; ni el que obra valerosamente, de que obra valerosamente ni de que actúa, en cuanto actúa, en virtud del valor, y así en mil casos más; tanto es así que la reflexión consciente (parakolouthēseis) tiene peligro de desvirtuar los actos de los que se es consciente (parakolouthoûnsi)" (I 4, 10, 20-30).

19 Opto por la traducción de Armstrong (1989) de sýneîsa como awareness frente a la explicitada ("perceptible") en la traducción citada. 
hace deseable las cosas, sino que también permite que el alma se eleve espontáneamente, a través de la anámnēsis y el lenguaje de éros, a lo uno que hay en él (VI 7, 22, 1; 15-20). Así pues, "como el alma es por naturaleza lo que es (...) en cuanto ve cualquier cosa de su estirpe o una huella de lo de su estirpe, se alegra y se queda emocionada y la relaciona consigo misma y tiene remembranza de sí misma y de los suyos" $(16,2,10)$. Este tipo de conciencia elevada se da tanto en el yo dianoético como en el noético y, por lo mismo, estrecha la relación de identificación con el intelecto y ofrece un camino para el ascenso ontológico y epistemológico en la realidad.

Y este es el animal. Estos niveles (layers) del yo componen al sujeto de los placeres, penas, temores, atrevimientos, apetitos, aversiones y dolor. Es el sujeto del razonamiento discursivo y praxis. Estos niveles son nuestros

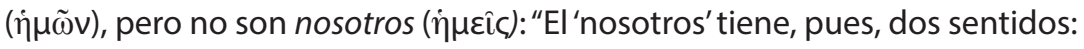
el que incluye la bestia y el que transciende ya la bestia. Ahora bien, 'bestia' es el cuerpo vivificado; pero el hombre verdadero (alēthés ánthrōpos) es otro (állos), el que está puro de dichas afecciones, poseyendo las virtudes intelectivas, las cuales residen en el alma misma que está tratando de separarse, tratando de separarse y separada aun estando acá todavía" (I 1, 10, 5-10).

El verdadero yo del hombre es noético. Al identificarse el hombre con su intelecto se identifica también con el alma superior y las hipóstasis. Dicho en breve: retorna a su "sí mismo". Este yo domina las pasiones (II 3, 9, 15-17). Así, "[p]orque todo cuanto es propio de esa vida (la del animal) es corporal. Propia, en cambio, de la otra alma, de la exterior al cuerpo, es la marcha a lo alto, a lo bello y a lo divino, que son algo en lo que nadie manda" (II 3, 9, 2428). Como este nivel del yo es puramente intelectivo, el tipo de conciencia que posee (sýnesis) abraza la realidad objetiva por su identidad con el Ser y las Formas. Es más, en los seres racionales, mientras más cerca el pensamiento y el ser estén juntos, más unificado estará el todo estructurado y, en este caso, su propio ser (III 8, 8). El que contempla las Formas se hace idéntico con los objetos de su intelección (V 3, 4, 20-30): "Se absorbe completamente a sí mismo en la contemplación al punto de remover toda dualidad y olvidar su identidad encarnada. Esto sugiere que no es solo 
la memoria la que está ausente de la contemplación, sino también cierto modo de autoconciencia" (Hutchinson 2018, 144; la traducción es mía).

Esta ausencia de conciencia en este nivel no es exactamente una negación, sino un ahondamiento en la realidad que le permite ser. La "huida de aquí" se forma progresivamente como una supraconciencia vinculada a realidades supremas. Esta forma trascendente de conciencia eleva al hombre al Uno solo cuando ha superado la alteridad de la Inteligencia y se encuentra más allá del mundo inteligible. El conocimiento de quien realmente es le permite ser auténticamente libre:"Así, pues, el alma es libre por la inteligencia cuando persigue el Bien desembarazadamente; y son de su albedrío los actos que pone por razón del Bien" (VI 8, 7). Es genuinamente libre cuando no se desea por indigencia, por estar falto de algo. La voluntariedad y albedrío existentes en las acciones libres tienen como referentes a la actividad interna -intelectiva y contemplativa- de la virtud $(\mathrm{VI} 8,6,20)$.

A partir de esta exposición de los niveles del yo, me parece que se puede plantear cierto concilio entre las afirmaciones de V 1, 1, 1-15 y I 8, 3, 35-40. El querer ser de sí mismo es un mal para el alma cuando este sí mismo se identifica con los niveles inferiores del yo. Mientras la parte intermedia del alma, esto es, el alma inferior, esté vuelta hacia lo sensible más de lo necesario, se fundirá en la materia. Esta es la segunda caída del alma. La sombra del mal moral perjudica al hombre vicioso de tal manera que se ve cada vez más impedido de ver. ¿Ver qué? Verse y, en su símismo, a su Padre.

Con lo visto, con la identificación del hombre con su intelecto y, en última instancia, con la Inteligencia, este puede acceder a la infalibilidad que posee el Noûs, y con ello al Ser más íntegro y a la Vida primera. En ese sentido, desde luego, se entiende por qué la generación y la alteridad ( V 1, 1, 4-5) son un mal para el hombre. Las partes sin la unidad son solo partes; una vida humana que se pierda en la multiplicidad sin reconocer la unidad que la sostiene es confusión pura. La alteridad del Intelecto es distinción necesaria para conformar el pensamiento (a-lētheía); la del hombre vicioso, dispersión. Plotino dice que no todo aquello que hay en el alma es inmediatamente perceptible conscientemente, sino que es necesario que la atención de uno esté vuelta hacia eso (V 1, 12, 5-10). El olvido (lếthē) de Dios 
para el hombre es una parcialización de la mirada, y es por eso, me parece, que es malo: va en contra de la tendencia unificadora de la realidad y, por lo mismo, contra sí mismo. Es menosprecio (atimía) (V 1, 1, 10).

Teniendo en cuenta la argumentación anterior sobre la conciencia del hombre, me parece que, en su autoidentificación con el compuesto, esta se atrofia. Tanto antílépsis como synaísthēsis, en tanto modos de conciencia, no pueden ejercer correctamente sus funciones unificadoras de la multiplicidad de estímulos internos y externos. Los diversos cambios de opinión y estados de perplejidad en el hombre son un obstáculo para ellas (IV 4, 17, 10-15). La identificación del hombre con los niveles inferiores de su yo le exige entera atención y complacencia frente a las representaciones imaginativas de lo sensible y afecciones. Esto es posible ya que el alma pura es agente de su propio bienestar y libertad (I 8, 4, 25-29). Si la materia vuelve semejante a sí a todo aquello que tome contacto con ella $(18,4,23)$, el hombre que se funda en ella a través del vicio ha de experimentar una pérdida progresiva de una conciencia de orden superior como la sýnesis y, con ella, del camino de retorno a su verdadera autodeterminación.

Así pues, para Plotino, aquellos hombres identificados con su yo dianoético y físico son causas pasivas de lo que les sucede y se encuentran sujetos a la predeterminación del destino y la fatalidad en el mundo ${ }^{20}$. Solo el alma superior es libre y, por ello, es agente activa en el orden del cosmos. Más aún, la libertad es un camino de purificación para el alma superior. Porque la estructura de la realidad es contemplativa -tal como está expresado en el tratado III 8-, sin el ejercicio y vida del pensamiento el alma muere. "Muere, pues, el alma como puede un alma morir: la muerte para ella, cuando todavía está inmersa en el cuerpo, consiste en hundirse en la materia y atestarse de ella, $y$, una vez salida del cuerpo, en yacer en ella (...)" $(18,13,20-25)$.

20 Tomo, junto a Corrigan, como modelo del asemejamiento del hombre a la informidad y carencia total de la materia al nacimiento del hombre tiránico en la República (1998, 227-230). 


\section{§4. ¿Posee valor alguno el conocimiento del mal?}

Tras la exposición precedente sobre el mal, podría parecer que toda relación con él es negativa para el alma humana. Plotino insiste a lo largo de las Enéadas en que el imperativo ético supremo humano consiste en huir de este mundo sensible y elevarse al Uno. Se debe, pues, huir para no asemejarse a la completa privación y carencia de la materia. Para ello, el conocimiento de quién es el hombre y quién es su padre, como he argüido, es esencial. Para el reconocimiento de la verdadera naturaleza humana, contar con el conocimiento -aunque aproximativo- del Bien, como de la Inteligencia, es imprescindible. En un mundo que está constituido forzosamente por contrarios, la materia ( $y$, con ella, el mal) existe por necesidad también $(I 8,7)$. Los contrarios contribuyen al orden cósmico (II 3, 16, 45). Con esto en mente, me pregunto si, en el caso del sabio (o filósofo), el mal tiene valor alguno. ¿Es posible que, para este hombre, quien domina la dialéctica, tenga algún valor epistémico la existencia del mal, de tal manera que le ayude a distinguir al hombre verdadero del revestimiento?

En II 4, adoptando Plotino la tesis platónica de que "lo semejante es aprehendido por lo semejante", dice que lo indeterminado también será aprehendido por lo indeterminado (10, 1-10). Teniendo en cuenta la indeterminación, informidad y no-ser de la materia, manifiesta lo siguiente: a pesar de que un razonamiento de esta clase pueda llegar a ser determinado, sería bastardo; la intuición, como método por el cual el alma superior conoce, sería en realidad una pseudointuición porque su objeto es indeterminado. En pocas palabras, el intentar abstraer la materia del cuerpo mediante un razonamiento o una "intuición" sería un completo fracaso. No es posible, la visión del alma estaría como en tinieblas y vería carencia de figura, color, luz, magnitud (II 4, 10, 5-20). El alma no puede conocer al Mal en sí porque en su manera de conocer, a través de la forma, busca la unidad en la multiplicidad y, con ella, tiende hacia el Bien. Pero, ¿puede conocer los males secundarios? 
En el siguiente pasaje, Plotino arguye:

“-¿Y con qué conocimos esos males? Y primero el vicio, ¿con qué lo conocimos? Porque la virtud sí la conocemos con la inteligencia misma y con la sabiduría, pues se conoce a sí misma. Pero el vicio, ¿cómo? -Pues del mismo modo que con una regla conocemos lo que es rectilíneo y lo que no, así también con la virtud conocemos lo que no se ajusta. - ¿Viéndolo o sin verlo? Me refiero al vicio. -El vicio completo sin verlo, pues es indefinido. Lo que de ningún modo se ajusta, lo conocemos, pues, por abstracción, mientras que el vicio incompleto lo conocemos por ser deficiente en eso" (I 8, 9, 1-9).

Quisiera resaltar dos puntos de este pasaje. Primero, el vicio total, esto es, la materia, no puede ser conocido debido a su indefinición. Pero el vicio incompleto (identificado con los males secundarios, males por participación en el Mal en sí), sí. Segundo, este vicio incompleto se conoce a través de la virtud. A primera vista, esto podría parecer un poco desconcertante, pero al revisar algunos extractos de IV 8, no lo es tanto. Plotino dice: "Y si se da prisa en huir (el alma), ningún daño se le sigue de haber adquirido conocimiento del mal y haber conocido la naturaleza de la maldad" $(5,25)$. En efecto, el conocimiento del mal está disponible para el hombre virtuoso; la experiencia, para quienes no lo son (IV 8, 7, 15).

¿Cómo se entiende la virtud de este hombre y cómo relacionarla con la capacidad de conocer por "ciencia"? En la Enéada I 2, Plotino establece una diferencia entre las virtudes superiores y las virtudes cívicas. Las virtudes superiores son virtudes intelectivas, esto es, son las virtudes de quien contempla las improntas del mundo inteligible. Tal como argumenté en la sección anterior, esto se da en quien se identifica con su intelecto y, con ello, con la Inteligencia. De ahí que se entienda que el conocimiento que tenga sea realmente por "ciencia". Mientras tanto, las virtudes cívicas son aquellas con las que se controlan los apetitos y las pasiones del compuesto. El hombre que posea las virtudes superiores necesariamente tendrá las inferiores en potencia, pero el caso contrario no se cumple $(7,10-14)$. Digo "en potencia" porque el objetivo del hombre que posee las virtudes cívicas es la vida de "bien", mientras que quien posee la verdadera virtud busca asemejarse a los dioses. 
Por eso, el hombre que puede conocer el mal conoce como con "(...) una regla conocemos lo que es rectilíneo $(. .) ".(I 8,3)$. Conoce la norma y el criterio con el que se mide el grado de verdad y virtud en las cosas, el cual solo puede poseerse una vez que se contemplen las Formas. Este hombre es el sabio o, dicho de otra manera, el filósofo. Este hombre vive en plena identificación con su intelecto. No necesita experimentar mal alguno para saber lo que son los males. Entonces, ¿cómo conoce?, ¿cómo es posible conocer el mal "por ciencia"? La clave la tiene la dialéctica.

Para Plotino, la dialéctica "(...) es la parte valiosa de la filosofía" (I 3, 5, 10). El dialéctico conoce la verdad; posee el hábito de declarar racionalmente qué es cada una de las cosas, en qué difiere de otras, qué de común tienen entre ellas $(13,4)$. Asimismo, discute con ciencia, no con opinión $(10,11)$ sobre el Bien y el no-bien, cuántos son los seres y cuántos son los distintos a los seres antes de elevarse sobre lo sensible e instalarse en lo inteligible tras desechar toda falsedad. Junto a los inteligibles, el dialéctico es capaz de reunir y dividir intelectivamente las Formas. Plotino manifiesta que la dialéctica conoce incidentalmente la falsedad y el sofisma “(...) cuando los ha cometido otro, juzgando la falsedad como ajena a las verdades que hay en ella, percatándose de cuanto no se ajusta la regla de la verdad cuando alguno se lo presenta" $(13,5,15)$. Esta regla de la verdad es la misma que la norma de la virtud en tanto coinciden en un mismo yo, el yo noético.

La actividad dialéctica es esencialmente purificadora: con el criterio de la verdad en mano el filósofo puede remover todo elemento ajeno a su verdadero yo. Pero para aplicar la norma necesita también conocimiento de los diferentes vicios a los que es propenso por estar en el mundo sensible como un compuesto. De ahí que, efectivamente, aunque poseyendo un valor secundario en relación al valor primario que posee un conocimiento tan divino como el del Bien, pueda llegar a ser útil para él. Y quizá no solo para él, sino también para el enamoradizo y el músico, potenciales candidatos para la unión con el Principio a través de la vía dialéctica, a quienes se puede exhortar, junto a Plotino: ¿Que cómo puedes ver la clase de belleza que posee un alma buena? Retírate a ti mismo y mira. Y si no te ves aún bello, entonces, como el escultor de una estatua que debe salir bella quita aquí, raspa allá, pule esto y limpia lo otro hasta que salga un rostro bello 
coronando la estatua, así tú también quita todo lo superfluo, alinea todo lo torcido, limpia y abrillanta todo lo oscuro y no ceses de 'labrar' tu propia estatua hasta que se encienda en ti el divinal esplendor de la virtud (...)" (I $6,9,5-15)$. Solo así es posible vivir la felicidad del sabio.

\section{§. Conclusión}

El objetivo general del presente trabajo fue realizar una aproximación a la antropología de Plotino desde algunos contrapuntes entre su metafísica y ética. Como mostré al principio de este trabajo, la estructura de la realidad es, para Plotino, una escala jerárquica ontológica y epistemológica de grados de contemplación. Toda vida contempla el principio de la cual procedió; cada hipóstasis puede volverse a su principio, salvo la materia.

La revisión de la estructura de la realidad permitió tener cierta base para conciliar el problema entre V 1, 1, 1-15 y I 8, 3, 35-40. Esta, sumado a la revisión de los niveles del yo, sirvió para plantear una salida exegética a afirmaciones que vistas juntas eran problemáticas. Dicho de manera genérica, el hombre es su alma, pero solo puede encontrar a su verdadero sí mismo en plena identificación con lo más alto de ella y, por consiguiente, en su Principio. El papel de la conciencia es crucial. Por lo tanto, el querer ser de símismo es un mal para el alma cuando este se identifica con los niveles inferiores del yo. Mientras más desciende en la escala jerárquica de niveles de conciencia, más se acerca a la informidad de la materia. En este descenso se confunde y ensimisma: no es capaz de aprehender más la Verdad y el conocimiento real que posee el alma superior al ascender y contemplar las Formas. La materia vuelve como ella a quien se involucra con ella; la progresiva pérdida de libertad es una de las maneras en que lo hace.

Al identificarse el hombre con su intelecto puede ser capaz de librarse de las "excrecencias" que se le han adherido al encarnarse en un cuerpo humano. No obstante, argüí que, para el sabio -esto es, para el filósofo-, quien vive en plena identificación con el yo noético de su alma, el conocimiento del mal no le es un estorbo, por el contrario, puede servirle para diferenciar entre el revestimiento y el verdadero yo del hombre. Solo este 
hombre virtuoso puede conocer con ciencia lo que es el mal sin tener que experimentarlo. A través del ejercicio dialéctico, este hombre es capaz de remover las bellas apariencias del mal en las cosas sensibles, reconocer la unidad tras lo múltiple y, a través de la unión con ella, experimenta su integración en la belleza y conciencia más genuina.

\section{Bibliografía}

Armstrong, Arthur, 1989. Ennead, Volume I: Porphyry on the Life of Plotinus. Ennead I. Cambridge: Harvard University Press.

Bréhier, Émile, 1958. The Philosophy of Plotinus. Chicago: The University of Chicago Press.

Corrigan, Kevin, 1998. Plotinus' Theory of Matter-Evil and the Question of Substance: Plato, Aristotle, and Alexander of Aphrodisias. Leuven: Peeters.

Dodds, Eric, 1960. Tradition and Personal Achievement in the Philosophy of Plotinus. The Journal of Roman Studies, 50, 1-7.

Gutiérrez, Raúl, 1990. El principio de Plotino y el inicio de una época. Areté, 2 (1), 49-67.

- 2017. El arte de la conversión: Un estudio sobre la República de Platón. Lima: Fondo Editorial de la Pontificia Universidad Católica del Perú.

Hutchinson, Danny, 2018. Plotinus on Consciousness. Cambridge: Cambridge University Press.

Igal, Jesús, 1992. Introducción general. En: Enéadas I-II. Madrid: Editorial Gredos, 7-115.

Kalligas, Paul, 2014. The Enneads of Plotinus. A Commentary. Volume I. Oxford: Princeton University Press.

Noble, Cristopher, 2013. How Plotinus' Soul Animates his Body: The Argument for the Soul-Trace at Ennead IV.4.18.1-9. Phronesis, 58 (3), 249-279. https://doi. org/10.1163/15685284-12341251

O'Brien, Dennis, 1969. Plotinus on evil: A Study of Matter and the Soul in Plotinus' Conception of Human Evil. The Downside Review, 87 (286), 68-110. https://doi. org/10.1177/001258066908728607

- 1996. Plotinus on matter and evil. En: The Cambridge Companion to Plotinus (Cambridge Companions to Philosophy), ed. Gerson Lloyd. Cambridge: Cambridge University Press, 171-195.

Platón, 2012. Fedro. Fedón-Fedro. Madrid: Alianza Editorial, 147-274.

- 2017. La República. Madrid: Alianza Editorial. 
Plotino, 1985. Enéadas III-IV. Madrid: Editorial Gredos.

- 1992. Vida de Plotino. Enéadas I-II. Madrid: Editorial Gredos.

- 1998. Eneadas V-VI. Madrid: Editorial Gredos.

Rist, John, 1974. Plotinus and Augustine on Evil. Plotino ed il Neoplatonismo in Oriente e in Occidente, Roma: Accademia Nazionale dei Lincei, 495-504.

Santa Cruz, María Isabel, 2012. El "cuidado de sí": Plotino, lector de Alcibíades I de Platón. Cuadernos de Filosofía, 29, 85-100.

Zamora, José María, 1997. La noción de procesión en Plotino. Areté, 9 (1), 85-105. 